\title{
Qualidade física dos solos irrigados de algumas regiões do Brasil Central
}

\author{
Cleudson J. Michelon', Reimar Carlesso', Mirta T. Petry ${ }^{1}$, Giane L. Melo', Renato B. Spohr ${ }^{1}$ \& Juliano G. de Andrade ${ }^{1}$
}

\begin{abstract}
RESUMO
A intensa utilização do solo com mecanização pesada e, principalmente, em condições inadequadas de umidade do solo causa, muitas vezes, a degradação de sua estrutura, resultando no aumento da sua compactação. Objetivou-se, neste trabalho, avaliar a qualidade física dos solos irrigados de algumas regiões do Brasil. O estudo foi realizado em áreas irrigadas sob pivô central, nos Estados de Goiás, GO, Minas Gerais, MG, e São Paulo, SP. Os perfis dos solos foram divididos em três camadas: superficial, intermediária e inferior e se realizaram as seguintes determinações: textura do solo, densidade do solo e de partículas e porosidade. Os solos foram agrupados em faixas de teor de argila sendo que, para cada faixa de teor de argila se estabeleceu um valor crítico de densidade do solo e de macroporosidade, acima do qual (densidade do solo) e abaixo do qual (macroporosidade), as amostras de solo foram caracterizadas com indicação de compactação. Do total de áreas amostradas na camada superficial, 14,2\% das áreas do Estado de GO, 9,5\% das áreas de MG e 34\% das áreas de SP, apresentaram indicação de compactação do solo em função da densidade do solo e macroporosidade.
\end{abstract}

Palavras-chave: compactação, densidade do solo, macroporosidade

\section{Physical quality of irrigated soils in some regions of Central Brazil}

\begin{abstract}
Intensive soil cultivation using heavy machinery, especially when soil moisture content is relatively high, has caused degradation of the physical properties of soil, mainly soil compaction. The objective of this study was to evaluate the physical quality of soil of some irrigated regions of Brazil and to collect information necessary to guide soil management decisions. This study was carried out in areas irrigated by center pivots in the States of Goiás, Minas Gerais and São Paulo. The soil profile was divided into three soil layers: superficial, intermediate and inferior. The following determinations were conducted: soil texture, bulk density, particle density and soil porosity. Soil types were grouped according to clay content. For each group of clay content, critical values of bulk density and soil macroporosity were established above which (bulk density) and below which (macroporosity) the soil sample were characterized as compacted. Considering the entire area sampled in the superficial layer, $14.2 \%$ of the samples collected in Goiás, $9.5 \%$ of soil samples collected in Minas Gerais and 34\% of the samples collected in São Paulo presented indications of soil compaction as a function of bulk density and macroporosity.
\end{abstract}

Key words: soil compaction, bulk density, soil porosity

1 UFSM, Rua Q, prédio 68, CEP 97105-900. Santa Maria, RS. Fone: (55) 3220-8399. E-mail: cleudsonjose@gmail.com; carlesso@ccr.ufsm.br; mirta.petry@gmail.com; gianelm@yahoo.com.br; renatospohr@yahoo.com.br; julianog.andrade@gmail.com 


\section{INTRODUÇÃO}

Nos sistemas agrícolas a água é essencial ao crescimento e desenvolvimento das plantas e regula os demais fatores físicos do solo que, por sua vez, influenciam diretamente o crescimento e a produtividade das culturas (Forsythe, 1967; Letey, 1985). A disponibilidade de água às culturas é variável, de acordo com as características do solo, condições climáticas e necessidade da planta; além disso, o aumento ou a redução da disponibilidade hídrica está muito relacionado com o manejo dado ao solo.

O potencial de áreas para o desenvolvimento da irrigação no Brasil é estimado em 14,6 milhões de ha em terras altas e de 14,9 milhões de ha em várzeas, totalizando 29,5 milhões de ha (Christofidis, 1999). Ainda segundo o autor, desse total apenas 2,090 milhões de ha se encontram sob irrigação em terras altas e 1,059 em várzeas, totalizando 3,149 milhões de ha, representando $10,7 \%$ do potencial de solos aptos para agricultura irrigada.

Considerando a irrigação realizada pelo método de aspersão via pivô central, o Estado de São Paulo apresenta a maior área irrigada com aproximadamente 250 mil ha, seguido de Goiás com 118 mil ha, Minas Gerais 88 mil ha e Bahia com 82 mil ha (Christofidis, 2002).

As lavouras irrigadas caracterizam-se pela intensificação dos cultivos e, por conseqüência, uma intensa utilização do solo, devido a que, atenção especial deve ser dada ao manejo do solo, das culturas e da água da irrigação, para evitar alterações nas características do solo, que causem a degradação das propriedades físicas, químicas e biológicas, afetando a produtividade das culturas. Um dos principais problemas enfrentados nas áreas irrigadas é a degradação da estrutura do solo, resultando no aumento da sua compactação; o principal efeito se refere ao tráfego de maquinários que, além de ser mais intenso, ocorre em solos com maior conteúdo de água, mais suscetíveis a compactação.

A compactação do solo é um processo resultante do histórico de tensões recebidas em uma área, através da mecanização ou pelo pisoteio animal (Reichert et al., 2003), e se refere à compressão do solo não saturado, durante a qual existe um aumento de sua densidade em conseqüência da redução de seu volume (Gupta \& Allmaras, 1987; Gupta et al., 1989), resultante da expulsão de ar dos poros do solo.

A compactação altera várias propriedades do solo, notadamente as relacionadas com a física do solo, como a densidade do solo, a porosidade e parâmetros hídricos ocasionando, com isto, alterações, na maioria das vezes indesejáveis, no espaço poroso do solo (Taylor \& Burnett, 1964; Grohmann \& Queiroz Neto, 1966). Essas alterações físicas, provocadas pela compactação do solo, afetam o fluxo ou a concentração de água, oxigênio, dióxido de carbono, nutrientes e temperatura do solo, podendo ainda limitar o crescimento e o desenvolvimento dos vegetais, além de causar problemas ambientais (Stepniewski et al., 2002).

Por possuírem características diferentes principalmente quanto à granulometria e ao teor de matéria orgânica, os solos cultivados apresentam comportamentos distintos quando submetidos a compactação (Bodman \& Constantin, 1966).
O conteúdo de água do solo é outro fator determinante no processo de compactação, pois existem faixas de umidade que tornam o solo mais ou menos suscetível à compactação.

A densidade do solo e a porosidade dos solos têm sido largamente utilizadas na avaliação da qualidade estrutural dos solos, pois tratam-se de propriedades do solo de fácil determinação e que recebem pequena influência do teor de água no momento da coleta da amostra de solo (Reichert et al., 2003).

Relacionando estados de compactação do solo com a produtividade das culturas, Silva (2003) encontrou uma redução de $18 \%$ na produtividade de trigo em um Latossolo Vermelho distrófico com $500 \mathrm{~g} \mathrm{~kg}^{-1}$ de argila que apresentou, na profundidade de $12,5 \mathrm{~cm}$, densidade de $1,62 \mathrm{Mg} \mathrm{m}^{-3}$, no maior estado de compactação em relação ao menor estado de compactação, no qual a densidade do solo foi de 1,44 $\mathrm{Mg} \mathrm{m}^{-3}$; já em um Latossolo Vermelho distroférrico típico, com $600 \mathrm{~g} \mathrm{~kg}^{-1}$ de argila, a redução na produtividade foi de $34 \%$ do maior estado de compactação cuja densidade do solo foi de $1,53 \mathrm{Mg} \mathrm{m}^{-3}$ para o menor estado de compactação, que apresentou densidade do solo de $1,31 \mathrm{Mg} \mathrm{m}^{-3}$.

Como os valores médios de densidade do solo de solos arenosos são, naturalmente, maiores que os valores de solos argilosos, deve-se evitar a utilização do valor absoluto da densidade do solo para avaliar o estado de compactação de um solo, utilizando-se o teor de argila como referência (Reinert et al., 2001); assim, de maneira generalizada, esses autores propõem os seguintes valores críticos de densidade do solo, caracterizando um solo como compactado: $1,45 \mathrm{Mg} \mathrm{m}^{-3}$ para solos com mais de $550 \mathrm{~g} \mathrm{~kg}^{-1}$ de argila; $1,55 \mathrm{Mg} \mathrm{m}^{-3}$ para solos entre 200 e $550 \mathrm{~g} \mathrm{~kg}^{-1}$ de argila e 1,65 $\mathrm{Mg} \mathrm{m}^{-3}$ para solos com menos de $200 \mathrm{~g} \mathrm{~kg}^{-1}$ de argila.

Streck (2003) trabalhando com compactação do solo em um Argissolo Vermelho-Amarelo Distrófico arênico, com 85,0 $\mathrm{g} \mathrm{kg}^{-1}$ de argila na camada de $10-20 \mathrm{~cm}$, encontrou uma redução de $40 \%$ na produtividade do feijoeiro no tratamento que sofreu compactação adicional em relação ao tratamento sem compactação adicional. A densidade do solo do tratamento com compactação adicional foi igual $1,74 \mathrm{Mg} \mathrm{m}^{-3}$ e a densidade do solo do tratamento sem compactação adicional, foi de $1,64 \mathrm{Mg} \mathrm{m}^{-3}$. O autor destaca, ainda, que o sistema radicular das plantas do tratamento que sofreu compactação se concentrou na camada superficial, enquanto as plantas do tratamento sem compactação apresentaram um aprofundamento do sistema radicular no perfil do solo; desta forma, o autor concluiu que a restrição ao crescimento radicular restringiu a produtividade da cultura.

Em relação à macroporosidade Reinert et al. (2001) afirma que o suprimento de oxigênio para as raízes tem sido considerado crítico quando o espaço aéreo do solo é de aproximadamente $0,10 \mathrm{dm} \mathrm{dm}^{-1}$, implicando em falta de oxigênio às raízes quando a aeração do solo é inferior a este limite; no entanto, existem culturas que exigem espaço aéreo superior a $10 \mathrm{dm} \mathrm{dm}^{-1}$ para se desenvolverem e outras que se desenvolvem com aeração inferior a $10 \mathrm{dm} \mathrm{dm}^{-1}$.

Este trabalho foi desenvolvido devido à crescente ampliação das áreas irrigadas no Brasil e à importância do conhecimento das características físicas dos solos para que os 
produtores e técnicos tenham subsídios para aperfeiçoar o manejo do solo, das culturas e da irrigação em suas áreas. O principal objetivo deste trabalho foi avaliar a qualidade física dos solos irrigados de algumas regiões do Brasil, utilizando como indicadores a densidade do solo e a macroporosidade.

\section{MATERIAL E MÉTODOS}

O trabalho foi realizado em áreas irrigadas sob pivô central, em três Estados do Brasil: Goiás, GO, Sul de Minas Gerais, MG, e sul de São Paulo, SP. Selecionaram-se pivôs representativos das propriedades, com base nas características morfológicas do solo, os quais foram georreferenciados através da tomada dos dados das coordenadas geográficas (latitude, longitude e altitude).

Em virtude do volume de material necessário e do custo para a realização das análises, estabeleceu-se que nos pivôs que possuíam áreas uniformes em relação à textura do solo, fosse realizada uma amostragem a cada 40 ha de área, enquanto se realizou, nos pivôs que apresentaram áreas desuniformes em relação à textura do solo, uma amostragem em cada ponto que apresentava diferença de textura. Obtiveramse as informações de uniformidade das áreas em relação à textura do solo através de uma consulta aos seus proprietários e visita às áreas dos pivôs.

No Estado de GO foram amostrados 305 pivôs, abertas 590 trincheiras e coletadas 4125 amostras representando uma área de 22.620 ha; no Estado de MG se coletaram 975 amostras em 140 trincheiras, distribuídas em 85 pivôs, equivalendo a uma área de 5.912 ha; em SP, 960 amostras foram coletadas em 140 trincheiras, distribuídas em 90 pivôs, equivalendo a uma área de 4.695 ha.

Para a coleta das amostras foram cavadas trincheiras de aproximadamente $80 \mathrm{~cm}$ de comprimento, $60 \mathrm{~cm}$ de largura e $75 \mathrm{~cm}$ de profundidade. Os perfis dos solos foram divididos em três camadas, em função da morfologia do solo, assim descritas: camada superficial, camada intermediária e camada inferior. A camada superficial variou de 0 a $25 \mathrm{~cm}$ de profundidade entre os perfis amostrados, a intermediária variou de 15 a $50 \mathrm{~cm}$ e a camada inferior oscilou de 35 a $75 \mathrm{~cm}$ de profundidade. As amostras de solo foram coletadas nas profundidades correspondentes à porção mediana de cada camada. Em cada trincheira se coletaram sete amostras de solo, dentre as quais três na camada superficial, duas na camada intermediária e outras duas na camada inferior.

Coletaram-se amostras com estrutura preservada, com o auxílio de um extrator, ao qual era acoplado um cilindro de metal de 5,56 cm de diâmetro, $3 \mathrm{~cm}$ de altura e volume $72,84 \mathrm{~cm}^{3}$, para determinação da porosidade e densidade do solo; já para as análises de textura e densidade de partículas, foram coletados aproximadamente $1000 \mathrm{~g}$ de solo com estrutura deformada, na porção mediana de cada camada do perfil do solo. Determinações analíticas de textura, densidade de partículas (Dp), densidade do solo (Ds) e porosidade, foram realizadas conforme métodos descritos pela EMBRAPA (1997).
Para a análise da textura do solo utilizou-se o método da pipeta; a densidade de partículas foi obtida pelo método do balão volumétrico e a densidade do solo pelo método do anel volumétrico, utilizando-se um cilindro com um volume de $72,84 \mathrm{~cm}^{3}$.

No laboratório, as amostras de solo não deformadas foram saturadas e colocadas na mesa de tensão a -0,001 MPa, durante 48 h e a -0,006 MPa no mesmo espaço de tempo; a umidade referente à tensão de $-0,006 \mathrm{MPa}$, correspondeu ao percentual de microporos desse solo, enquanto a porosidade total (Pt) foi calculada a partir da densidade do solo e Dp, através da expressão $\mathrm{Pt}=(\mathrm{Dp}-\mathrm{Ds}) / \mathrm{Dp}$; enfim, a macroporosidade foi calculada pela diferença entre a porosidade total e a microporosidade.

Para a avaliação de compactação dos solos utilizaram-se, como parâmetros, a densidade do solo e a macroporosidade. Amostras preliminares foram coletadas em algumas regiões para verificação da amplitude de variação da textura do solo e dos valores de densidade do solo e de macroporosidade. Com base nessas informações, os solos foram agrupados em faixas de textura, em função do teor de argila, assim descritas: 0-200, 200-300, 300-400, 400-500, 500-600, 600-700 e $>700 \mathrm{~g} \mathrm{~kg}^{-1}$ de argila. Em cada faixa de teor de argila se estabeleceu um valor crítico de densidade do solo e macroporosidade dos solos, com base na literatura existente, conforme a Tabela 1.

Tabela 1. Valores de densidade do solo e macroporosidade estabelecidos como críticos para a indicação de ocorrência de compactação dos solos em cada faixa de teor de argila dos solos. (Michelon, 2005)

\begin{tabular}{ccc}
\hline $\begin{array}{c}\text { Faixa de argila } \\
\left(\mathbf{g ~ k g ~}^{-1}\right)\end{array}$ & $\begin{array}{c}\text { Densidade do solo } \\
\left(\mathbf{M g ~ m}^{-3}\right)\end{array}$ & $\begin{array}{c}\text { Macroporosidade } \\
\left(\mathbf{d m ~ d m}^{-1}\right)\end{array}$ \\
$0-200$ & 1,60 & 0,10 \\
$200-300$ & 1,55 & 0,10 \\
$300-400$ & 1,50 & 0,08 \\
$400-500$ & 1,45 & 0,08 \\
$500-600$ & 1,40 & 0,06 \\
$600-700$ & 1,35 & 0,06 \\
$>700$ & 1,30 & 0,06 \\
\hline
\end{tabular}

A partir dos resultados de densidade do solo e macroporosidade, as amostras de solo foram classificadas, em relação à indicação de ocorrência de compactação, nos níveis assim descritos: C-D: compactada em função da densidade do solo: quando as amostras de solo apresentavam valores de densidade do solo e macroporosidade superiores aos níveis críticos estabelecidos para cada faixa de argila; C-M: compactada em função da macroporosidade: quando as amostras de solo indicavam valores de macroporosidade e densidade do solo inferiores aos níveis críticos estabelecidos para cada faixa de argila; C-DM: compactada em função da densidade do solo e macroporosidade: quando a amostra de solo mostrava densidade do solo superior e macroporosidade inferior aos níveis críticos estabelecidos para cada faixa de argila.

Os dados foram agrupados por camada do perfil de solo e classes de argila em que foram calculadas as freqüências 
percentuais para cada parâmetro. Utilizou-se o teste de Duncan em nível de 5\% de probabilidade de erro para comparar as médias dos parâmetros densidade do solo e porosidade entre as camadas do perfil do solo.

\section{RESULTADOS E DISCUSSÃO}

Observou-se a maior freqüência das áreas amostradas na camada superficial, nos Estados de GO e MG, na faixa de 400 a $500 \mathrm{~g} \mathrm{~kg}^{-1}$ de argila com 35,09\% das áreas amostradas de GO e 29, 76\% das áreas de MG (Tabela 2); no Estado de SP, as faixas de 400 a 500 e de 500 a $600 \mathrm{~g} \mathrm{~kg}^{-1}$ de argila apresentaram as maiores freqüências de áreas amostradas, com 24,64\% das áreas em cada faixa de argila, na camada superficial (Tabela 2).

Tabela 2. Freqüência e freqüência relativa das amostras de solo coletadas nos Estados de GO, MG e SP, em cada classe de argila, nas três camadas do perfil de solo

\begin{tabular}{|c|c|c|c|c|c|c|}
\hline \multirow{3}{*}{$\begin{array}{c}\text { Faixas } \\
\text { de argila } \\
\left(\mathrm{g} \mathrm{kg}^{-1}\right)\end{array}$} & \multicolumn{6}{|c|}{ Camadas do perfil do solo } \\
\hline & \multicolumn{2}{|c|}{ Superficial } & \multicolumn{2}{|c|}{ Intermediária } & \multicolumn{2}{|c|}{ Inferior } \\
\hline & Freq. & $\begin{array}{c}\text { Freq. } \\
\text { Relativa }\end{array}$ & Freq. & $\begin{array}{c}\text { Freq. } \\
\text { Relativa }\end{array}$ & Freq. & $\begin{array}{l}\text { Freq. } \\
\text { Relativa }\end{array}$ \\
\hline \multicolumn{7}{|c|}{ Estado de G0 } \\
\hline $0-200$ & 6 & 2,10 & 2 & 0,70 & 0 & 0,00 \\
\hline $200-300$ & 40 & 14,03 & 35 & 12,28 & 34 & 11,93 \\
\hline $300-400$ & 85 & 29,82 & 74 & 25,96 & 72 & 25,26 \\
\hline $400-500$ & 100 & 35,09 & 92 & 32,28 & 75 & 26,32 \\
\hline $500-600$ & 38 & 13,33 & 52 & 18,25 & 61 & 21,40 \\
\hline $600-700$ & 12 & 4,22 & 21 & 7,37 & 31 & 10,88 \\
\hline$>700$ & 4 & 1,41 & 9 & 3,16 & 12 & 4,21 \\
\hline Total & 285 & & 285 & & 285 & \\
\hline \multicolumn{7}{|c|}{ Estado de MG } \\
\hline $0-200$ & 9 & 10,72 & 9 & 10,72 & 9 & 10,72 \\
\hline $200-300$ & 7 & 8,33 & 4 & 4,76 & 2 & 2,38 \\
\hline $300-400$ & 8 & 9,52 & 10 & 11,91 & 9 & 10,72 \\
\hline $400-500$ & 25 & 29,76 & 12 & 14,28 & 5 & 5,95 \\
\hline $500-600$ & 23 & 27,38 & 27 & 32,14 & 28 & 33,33 \\
\hline $600-700$ & 12 & 14,29 & 20 & 23,81 & 27 & 32,14 \\
\hline$>700$ & 0 & 0,00 & 2 & 2,38 & 4 & 4,76 \\
\hline Total & 84 & & 84 & & 84 & \\
\hline \multicolumn{7}{|c|}{ Estado de SP } \\
\hline $0-200$ & 3 & 4,350 & 1 & 1,45 & 1 & 1,45 \\
\hline $200-300$ & 5 & 7,240 & 7 & 10,14 & 5 & 7,25 \\
\hline $300-400$ & 10 & 14,49 & 7 & 10,14 & 7 & 10,14 \\
\hline $400-500$ & 17 & 24,64 & 12 & 17,40 & 13 & 18,84 \\
\hline $500-600$ & 17 & 24,64 & 18 & 26,09 & 18 & 26,09 \\
\hline $600-700$ & 13 & 18,84 & 18 & 26,09 & 16 & 23,19 \\
\hline$>700$ & 4 & 5,80 & 6 & 8,69 & 9 & 13,04 \\
\hline Total & 69 & & 69 & & 69 & \\
\hline
\end{tabular}

Os teores médios de areia, silte e argila, respectivamente, do perfil do solo, foram 322,54, 166,46 e $511 \mathrm{~g} \mathrm{~kg}^{-1}$ para o Estado de SP; 227,02, 292,98 e $480 \mathrm{~g} \mathrm{~kg}^{-1}$ para o Estado de $\mathrm{MG}$ e 341,63, 225,06 e 433,31 $\mathrm{g} \mathrm{kg}^{-1}$ para o Estado de GO (Figura 1). Observou-se pequeno incremento no teor de argila dos solos amostrados nos três Estados, com o aumen- to da profundidade do perfil do solo (Figura 1).

A textura do solo é uma das principais características dos horizontes (Oliveira et al., 1992) e, juntamente com a estrutura, compõem os principais parâmetros que afetam a porosidade do solo. Segundo Carlesso \& Zimmermann (2000), em solos de textura média e argilosa, onde é comum a ocorrência de agregados porosos e elevado teor de matéria orgânica, os espaços porosos por unidade de volume são elevados; já em solos de textura arenosa a porosidade total é usualmente reduzida.

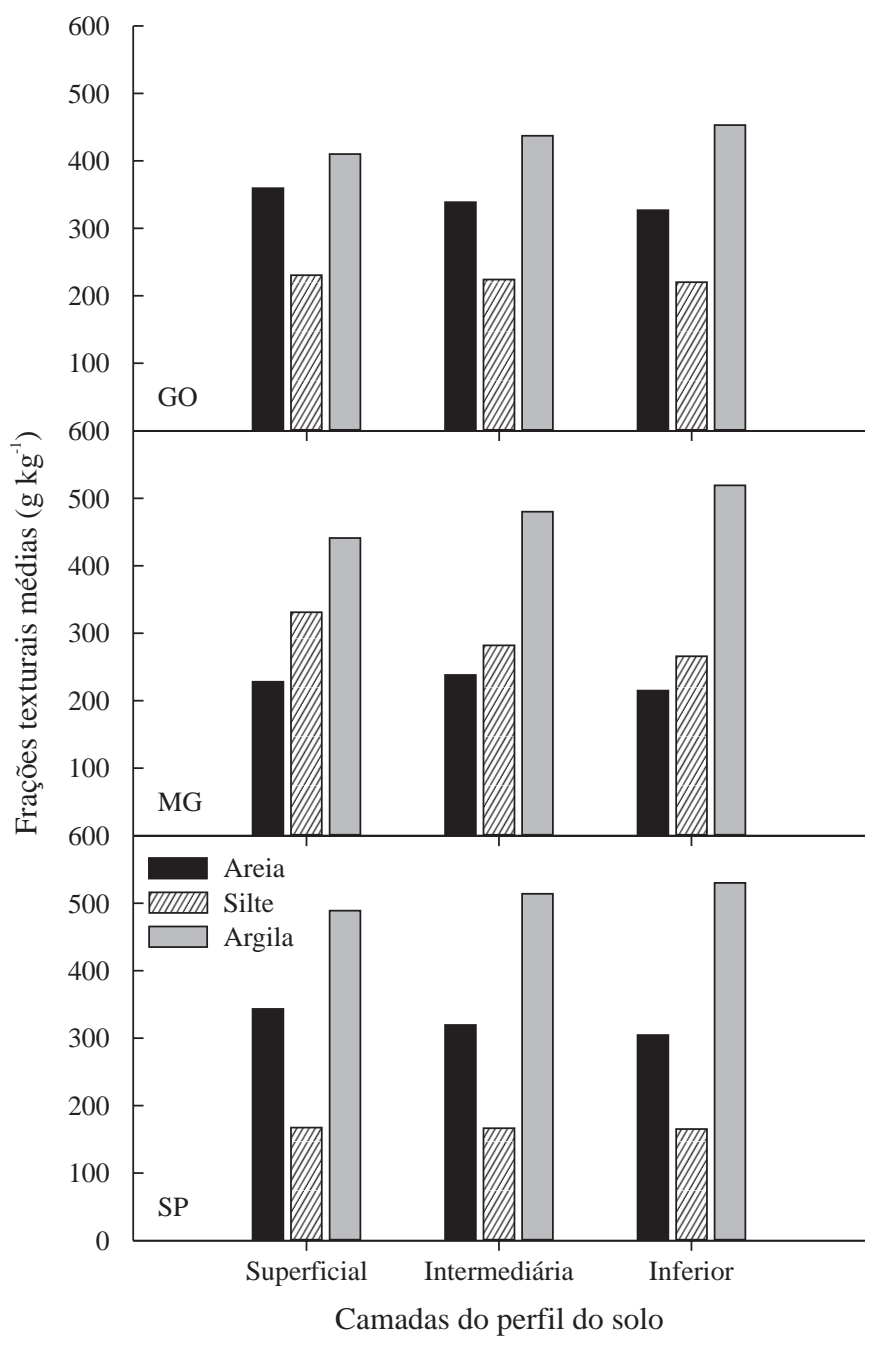

Figura 1. Frações texturais médias para as camadas superficial, intermediária e inferior, observadas nas amostras de solo coletadas em áreas irrigadas nos Estados de Goiás, GO, Minas Gerais, MG e São Paulo, SP

O intenso manejo do solo, característico de áreas irrigadas, provocou alterações na porosidade do solo ao longo do seu perfil; observa-se, na Figura 2, que os valores de macroporosidade e de porosidade total da camada superficial do perfil do solo foram inferiores aos valores das demais camadas desse perfil, diferindo estatisticamente, as exceções foram os valores de porosidade total da camada superficial das amostras coletadas em MG, que não diferiram dos valores da camada intermediária.

Um dos primeiros indicativos da ocorrência do processo 
de compactação é a redução do tamanho de poros (Silva, 2003). A estrutura é modificada, os macroagregados destruídos e o solo se transforma em estrutura maciça (Tavares Filho et al., 1999). Segundo Soane \& van Ouwerkerk (1994), um solo compactado apresenta aumento de sua densidade e resistência mecânica a penetração, além de redução na porosidade, principalmente a macroporosidade ou porosidade de aeração.

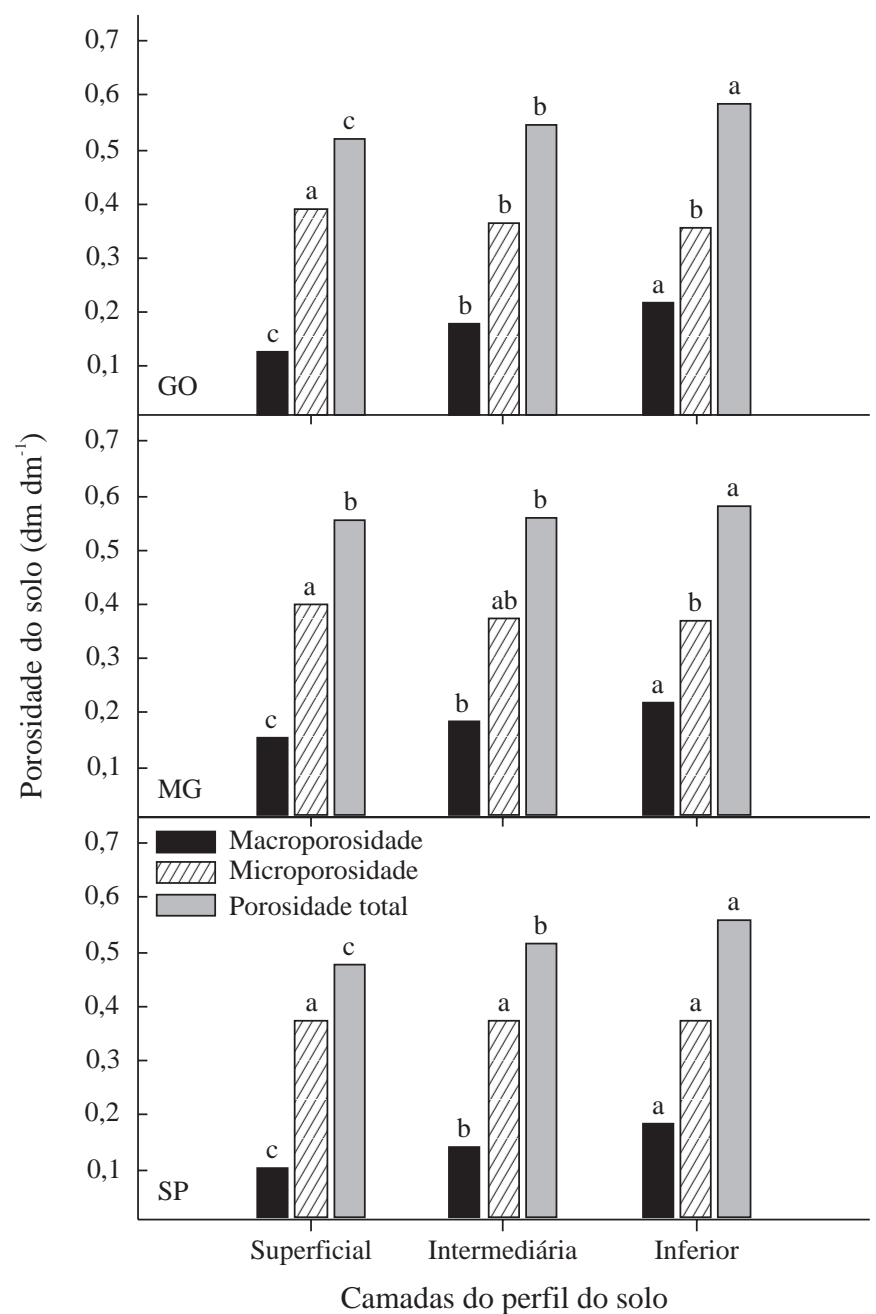

Obs: As médias seguidas da mesma letra entre as camadas do perfil do solo não diferem entre si pelo teste Duncan a $5 \%$ de probabilidade

Figura 2. Macroporosidade, microporosidade e porosidade total do solo, nas camadas superficial, intermediária e inferior, de amostras de solo coletadas em áreas irrigadas nos Estados de Goiás, GO, Minas Gerais, MG e São Paulo, SP

A macroporosidade média dos solos amostrados nos Estados de SP, MG e GO, nas três camadas do perfil do solo, foi superior a $0,10 \mathrm{dm} \mathrm{dm}^{-1}$ (Figura 2), limite de macroporosidade considerado crítico por Baver et al. (1972), indicando que na média dos valores de macroporosidade esses solos não apresentaram problemas de compactação. No entanto, em várias áreas amostradas, os valores de macroporosidade observados foram inferiores ao limite crítico, indicando a presença de compactação do solo.

Observa-se, na Figura 3, que a densidade do solo média das áreas amostradas no Estado de GO, nas camadas superficial, intermediária e inferior, foi 1,25, 1,20 e 1,10 $\mathrm{Mg} \mathrm{m}^{-3}$, respectivamente. Esses valores foram inferiores ao valor 1,45 $\mathrm{Mg} \mathrm{m}^{-3}$, indicado como valor crítico para os solos com teor de argila entre 400 e $500 \mathrm{~g} \mathrm{~kg}^{-1}$ (Tabela 1 ).

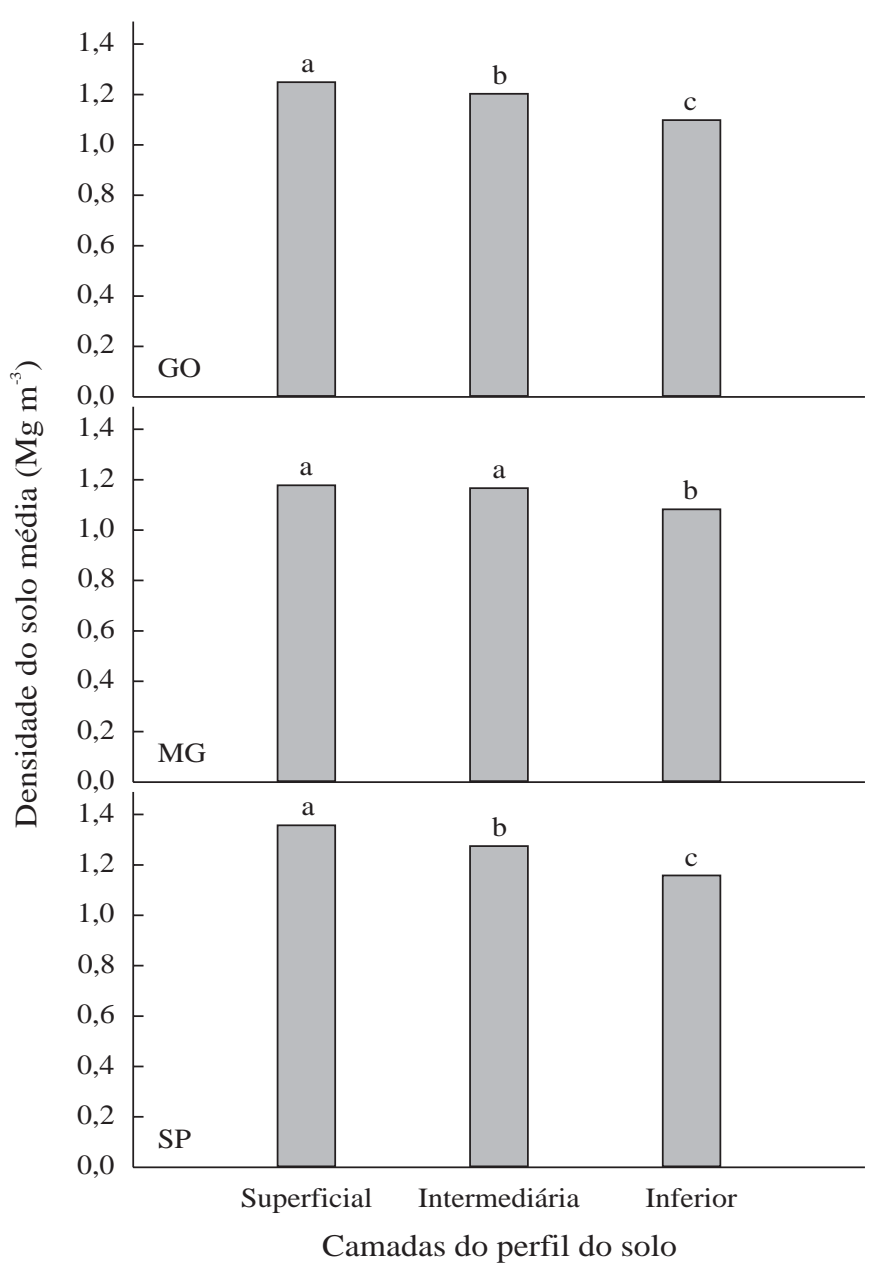

Obs: As médias seguidas de mesma letra não diferem entre si pelo teste Duncan em $5 \%$ de probabilidade

Figura 3. Médias da densidade do solo nas camadas superficial, intermediária e inferior de amostras de solo coletadas em áreas irrigadas nos Estados de Goiás, GO, Minas Gerais, MG e São Paulo, SP

No Estado de MG, a densidade do solo média das amostras coletadas foi de $1,17,1,16$ e $1,08 \mathrm{Mg} \mathrm{m}^{-3}$ para as camadas superficial, intermediária e inferior do perfil dos solos irrigados amostrados, respectivamente (Figura 3). Esses valores são inferiores ao limite de $1,45 \mathrm{Mg} \mathrm{m}^{-3}$, reconhecido como valor crítico para solos com 400 e $500 \mathrm{~g} \mathrm{~kg}^{-1}$ (Tabela 1) porém vários pivôs apresentaram valores de densidade do solo superiores ao limite crítico, indicando a presença de áreas compactadas em função da densidade do solo.

A densidade do solo média das áreas amostradas no Estado de SP (Figura 3) foi 1,36, 1,27 e 1,16 $\mathrm{Mg} \mathrm{m}^{-3}$ para as camadas superficial, intermediária e inferior do perfil do solo, respectivamente. Trata-se de valores inferiores ao limite de $1,40 \mathrm{~g} \mathrm{~cm}^{-3}$, estabelecido como crítico para solos com 500 a $600 \mathrm{~g} \mathrm{~kg}^{-1}$ de argila, mas vários pivôs apresentaram valores 
de densidade do solo superiores ao limite crítico, mostrando haver áreas com indicação de compactação do solo em função da densidade do solo.

Com exceção das áreas amostradas em MG, em que os valores de densidade do solo da camada superficial e intermediária não diferiram estatisticamente, os solos amostrados apresentaram valores de densidade do solo mais elevados na camada superficial, diferindo estatisticamente das demais camadas do perfil do solo (Figura 3); a maior densidade do solo na camada superficial pode ser explicada pelo maior tráfego de máquinas e equipamentos necessários ao manejo do solo e das culturas e ao pisoteio de animais nas áreas em que se utiliza a integração lavoura-pecuária, o que, entretanto não se observou em MG devido, possivelmente, ao revolvimento do solo das áreas amostradas, realizado no cultivo anterior.

No Estado de GO, 9,30\% das áreas amostradas apresentavam indicação de compactação em função da macroporosidade do solo e 4,3\% em função da densidade do solo e da macroporosidade do solo, na camada superficial (Figura 4); na camada intermediária, 1,2\% das áreas amostradas apresentava indicação de compactação em função da macroporosidade do solo.

Do total de áreas amostradas no Estado de MG, 4,75\% apresentaram indicação de compactação do solo em função da densidade do solo e da macroporosidade, na camada superficial (Figura 4); já na camada intermediária do perfil do solo, 8,4\% dos pivôs indicaram presença de compactação em relação à densidade do solo e 1,2\% em função da macroporosidade (Figura 4).

No Estado de SP foram observados, para a camada superficial do perfil do solo, 6\% das áreas amostradas com indicativo de compactação em função da densidade do solo, $12 \%$ com indicação de compactação em função da macroporosidade e $16 \%$ com indicação de compactação em função da densidade do solo e macroporosidade do solo (Figura 4); notou-se, na camada intermediária, que 3\% das áreas amostradas apresentaram indicação de compactação em relação à densidade do solo e 5\% com indicação de compactação em função da densidade do solo e macroporosidade do solo.

O sistema de cultivo utilizado na maioria das áreas amostradas é o preparo convencional. O revolvimento realizado no solo a cada safra desfaz possíveis áreas adensadas na camada superficial do solo, minimizando os efeitos da compactação nessa camada, porém áreas compactadas são transferidas para camadas intermediárias do perfil do solo, abaixo da profundidade atingida pelos implementos de preparo do solo, compactando essas camadas. Segundo Wolschick (2000), o preparo contínuo do solo para cultivos anuais provoca a desestruturação da camada superficial, transformando-a em duas fases distintas: na superficial pulverizada e na subsuperficial compactada. Na camada inferior dos solos amostrados não se constataram áreas com problemas de compactação dos solos, sinal de que a metodologia aqui utilizada que atribuiu valores críticos de densidade do solo e macroporosidade, para identificar áreas compactadas, apresentou bom comportamento.

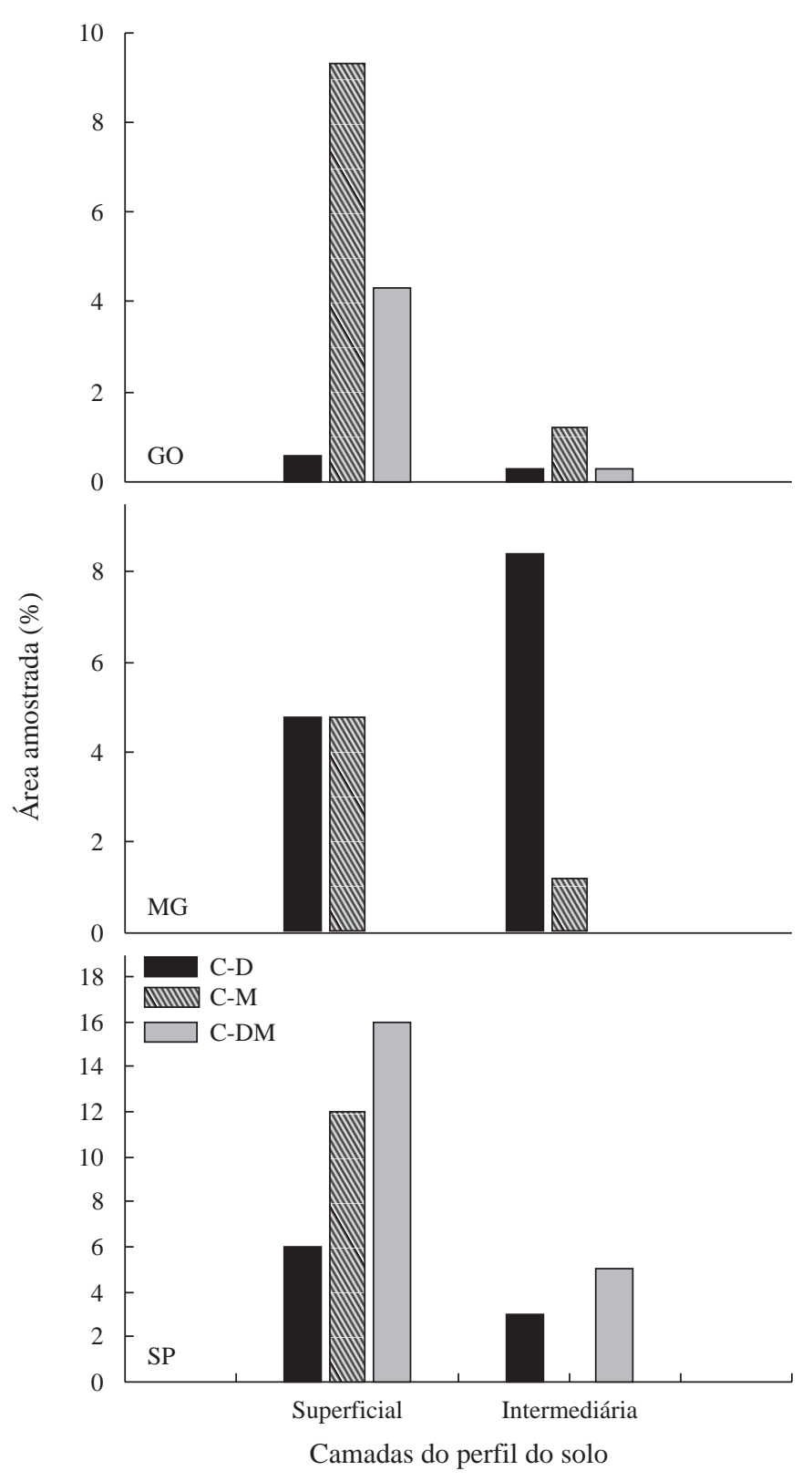

Figura 4. Situação das áreas amostradas dos Estados de Goiás, GO, Minas Gerais, MG e São Paulo, SP, nas camadas superficial, intermediária e inferior, em relação aos níveis críticos de densidade e macroporosidade do solo. (C-D: compactado em função da densidade do solo; C-M: compactado em função da macroporosidade; C-DM: compactado em função da densidade do solo e macroporosidade)

\section{CONCLUSÕES}

Do total de áreas amostradas na camada superficial do perfil do solo, 14,2\% no Estado de Goiás, 9,5\% no Estado de Minas Gerais e 34\% no Estado de São Paulo, apresentaram indicação de compactação em função da densidade do solo e macroporosidade do solo.

\section{LITERATURA CITADA}

Baver, L. D.; Gardner, W. H.; Gardner, W. R. Soil physics. 4.ed. New York: J. Wiley, 1972. 529p. 
Bodman, G. B.; Constatin, G. K. Influence of particle size distribution in soil compaction. Hilgardia, v.36, p567-591, 1966.

Carlesso, R.; Zimmermann, F. L. Água no solo: Parâmetros para o dimensionamento de sistemas de irrigação. Santa Maria: UFSM, 2000. 88p.

Christofidis, D. Recursos hídricos e irrigação no Brasil. In: Workshop Disponibilidade de Água e Irrigação no Nordeste, 1999, Brasília. Resumos... Brasília: ISPN, 1999. 34p.

Christofidis, D. Irrigação, a fronteira hídrica na produção de alimentos. Irrigação e Tecnologia Moderna, v.1, n.54, p.46-55, 2002.

EMBRAPA - Empresa Brasileira de Pesquisa Agropecuária. Manual de métodos de análises de solo. 2.ed. Rio de Janeiro: Ministério da Agricultura e do Abastecimento, 1997. 212p.

Forsythe, W. M. Lãs propriedades físicas, los factores físicos de crescimento y la productividad del suelo. Fitotecnia Latino Americana, v.4, p.165-176, 1967.

Grohmann, F.; Queiroz Neto, J. P. Efeito da compactação artificial de dois solos limo-argilosos sobre a penetração das raízes de arroz. Bragantia, v.25, n.38, p.421-431, 1966.

Gupta, S. C.; Allmaras, R. R. Models to access the susceptibility of soil to excessive compaction. Advances in Soil Science, v.6, p.65-100, 1987.

Gupta, S. C.; Hadas, A.; Schafer, R. L. Modeling soil mechanical behaviour during compaction. In: Larson, W. E.; Blake, G. R.; Allmaras, R. R.; Voorhees, W. B.; Gupta, S. C. Mechanics and related process in structured agricultural soils. NATO Applied Sciences 172. The Netherlands: Kluwer Academic Publishers, 1989. 15p.

Letey, J. Relationship between soil physical properties and crop productions. Advances in Soil Science, v.1, p.277-294, 1985.

Michelon, C. J. Qualidade física dos solos irrigados do Rio Grande do Sul e do Brasil Central. Santa Maria: UFSM, 2005. 92p. Dissertação Mestrado
Oliveira, J. B. de, Jacomine, P. K. T., Camargo, M. N. Classes gerais de solos do Brasil. Guia auxiliar para seu reconhecimento. 2.ed. Jaboticabal: FUNEP/UNESP. 1992. 201p.

Reichert, J. M.; Reinert, D. J.; Braida, J. A. Qualidade dos solos e sustentabilidade de sistemas agrícolas. Ciência e Ambiente, v.27, p.29-48, 2003.

Reinert, D. J.; Reichert, J. M.; Silva, V. R. Propriedades físicas de solos em sistema de plantio direto irrigado. In: Carlesso, R.; Petry, M. T.; Rosa, G. M.; Ceretta, C. A.(ed.). Irrigação por aspersão no Rio Grande do Sul. Santa Maria: UFSM, 2001, 165p.

Silva, V. R. Propriedades físicas e hídricas em solos sob diferentes estados de compactação. Santa Maria: UFSM, 2003. 171p. Tese Doutorado

Soane, B. D.; van Ouwerkerk, C. Soil compaction problems in world agriculture. In: Soane, B. D.; van Ouwerkerk, C. Soil compaction in crop production. Netherlands: Elsevier, 1994. 21p.

Stepniewski, W.; Horn, R.; Martyniuk, S. Managing soil biophysical properties for environmental protection. Agriculture Ecosystems \& Environment, v.88, p.175-181, 2002.

Streck, C. A. Compactação do solo e seus efeitos no desenvolvimento radicular e produtividade da cultura do feijoeiro e da soja. Santa Maria: UFSM, 2003. 83p. Dissertação Mestrado

Tavares Filho, J.; Ralisch, R.; Guimarães, M. F.; Medina, C. C.; Balbino, L. C.; Neves, C. S. V. J. Método do perfil cultural para a avaliação do estado físico de solos em condições tropicais. Revista Brasileira de Ciência do Solo, v.23, p.111-119, 1999.

Taylor, H. M.; Burnetti, E. Influence of soil strength on root growth habits of plants. Soil Science, v.98, n.1, p.174-180, 1964.

Wolschick, D. Perdas de nitrogênio por lixiviação durante o ciclo de desenvolvimento da cultura do milho em condições de excesso hídrico. Santa Maria: UFSM. 2000. 76p. Dissertação Mestrado 